\title{
Peritoneal carcinomatosis: patients selection, perioperative complications and quality of life related to cytoreductive surgery and hyperthermic intraperitoneal chemotherapy Gabriel Glockzin, Hans J Schlitt and Pompiliu Piso*
}

Address: Department of Surgery, University of Regensburg Medical Center, Regensburg, Germany

Email: Gabriel Glockzin - gabriel.glockzin@klinik.uni-regensburg.de; Hans J Schlitt - hans.schlitt@klinik.uni-regensburg.de; Pompiliu Piso* - pompiliu.piso@klinik.uni-regensburg.de

* Corresponding author

Published: 8 January 2009

World Journal of Surgical Oncology 2009, 7:5 doi:10.1 186/1477-7819-7-5

This article is available from: http://www.wjso.com/content/7///5

(c) 2009 Glockzin et al; licensee BioMed Central Ltd.

This is an Open Access article distributed under the terms of the Creative Commons Attribution License (http://creativecommons.org/licenses/by/2.0), which permits unrestricted use, distribution, and reproduction in any medium, provided the original work is properly cited.
Received: 9 October 2008

Accepted: 8 January 2009

\begin{abstract}
Background: Peritoneal tumor dissemination arising from colorectal cancer, appendiceal cancer, gastric cancer, gynecologic malignancies or peritoneal mesothelioma is a common sign of advanced tumor stage or disease recurrence and mostly associated with poor prognosis.
\end{abstract}

Methods and results: In the present review article preoperative workup, surgical technique, postoperative morbidity and mortality rates, oncological outcome and quality of life after CRS and HIPEC are reported regarding the different tumor entities.

Conclusion: Cytoreductive surgery (CRS) and hyperthermic intraperitoneal chemotherapy (HIPEC) provide a promising combined treatment strategy for selected patients with peritoneal carcinomatosis that can improve patient survival and quality of life. The extent of intraperitoneal tumor dissemination and the completeness of cytoreduction are the leading predictors of postoperative patient outcome. Thus, consistent preoperative diagnostics and patient selection are crucial to obtain a complete macroscopic cytoreduction (CCR-0/I).

\section{Background}

Peritoneal carcinomatosis is a common sign of advanced tumor stage, disease progression or recurrence in numerous tumor entities of gastrointestinal or gynecological origin. Moreover, there are primary peritoneal malignancies such as malignant peritoneal mesothelioma or primary peritoneal carcinoma. In general, the diagnosis of peritoneal tumor manifestation is associated with poor prognosis. In the European multicenter EVOCAPE I study the median survival rates were 5.2 months for advanced colorectal cancer (CRC, $\mathrm{n}=118$ ) and 3.1 months for advanced gastric cancer (GC, $\mathrm{n}=125)$, respectively[1]. The median survival rate in patients with stage IV ovarian cancer (OC) range from 12 to 23 months [2-4]. For diffuse malignant peritoneal mesothelioma (DMPM) median survival rates of less than one year are reported in most existing studies [5-7]. However, in a Phase II trial with systemic application of permetrexed and gemcitabine the median survival rate was 26.8 months in patients with malignant peritoneal mesothelioma [8]. The treatment of choice for patients with peritoneal surface malignancies is palliative systemic chemotherapy. In the past, surgery was performed in palliative intention for prevention or therapy of tumor-related complications such as gastrointestinal obstruction, bleeding or tumor perforation [9]. Solely, in ovarian cancer cytoreductive surgery was already estab- 
lished as an inherent part of the standard treatment regimen [10]. In the early 1990's Sugarbaker et al. introduced cytoreductive surgery (CRS) and hyperthermic intraperitoneal chemotherapy (HIPEC) as a new innovative therapeutic option for selected patients with peritoneal carcinomatosis $[11,12]$. Over the years peritoneal carcinomatosis treatment centers were established in the United States, Europe and Japan. Feasibility, efficacy and safety of CRS and HIPEC have been proved in numerous clinical trials. In the present review article patient selection, treatment strategy, mortality and morbidity rates and oncological outcome is reported regarding the different tumor entities.

\section{Cytoreductive surgery}

CRS consists of numerous surgical procedures depending on the extent of peritoneal tumor manifestation. In appendiceal malignancies, the omental cake, a disseminated tumor infiltration of the greater omentum, represents the most affected abdominal area (Fig. 1). Surgery may include parietal and visceral peritonectomy, greater omentectomy, splenectomy, cholecystectomy, resection of liver capsule, small bowel resection, colonic and rectal resection, (subtotal) gastrectomy, lesser omentectomy, pancreatic resection, hysterectomy, ovariectomy and urine bladder resection. In patients with mucinous tumors and infiltration of the umbilicus, an omphalectomy is necessary. Extraperitoneal dissection may enable the anterior parietal peritonectomy and avoid a tumor contamination of the abdominal wall (Fig. 2). The extent of intraperitoneal tumor manifestation is determined using the peritoneal cancer index (PCI), a combined numerical score of lesion size (LS-0 to LS-3) and tumor localization (region $0-12$ ) $[13,14]$. The aim of CRS is to

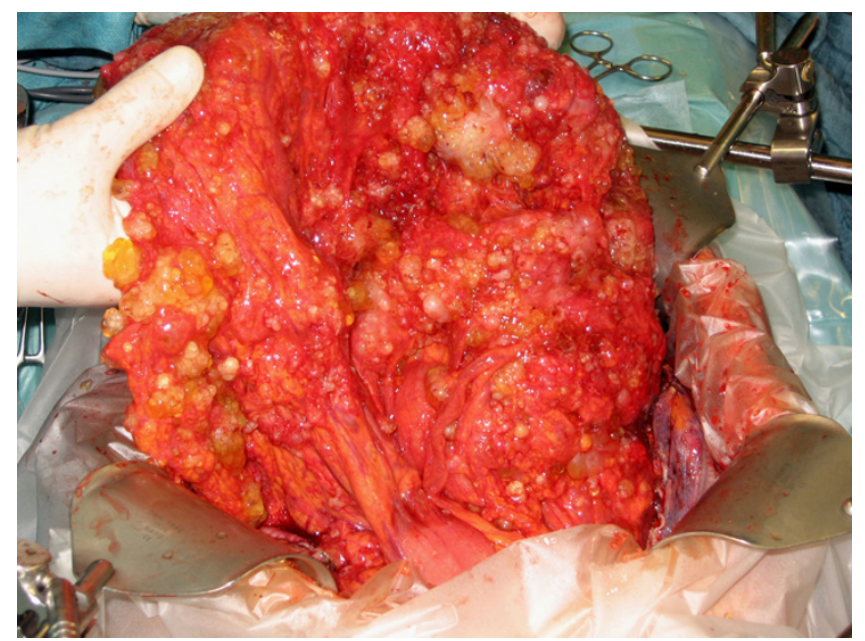

Figure I

'Omental cake' in a patient with peritoneal carcinomatosis arising from appendiceal cancer.

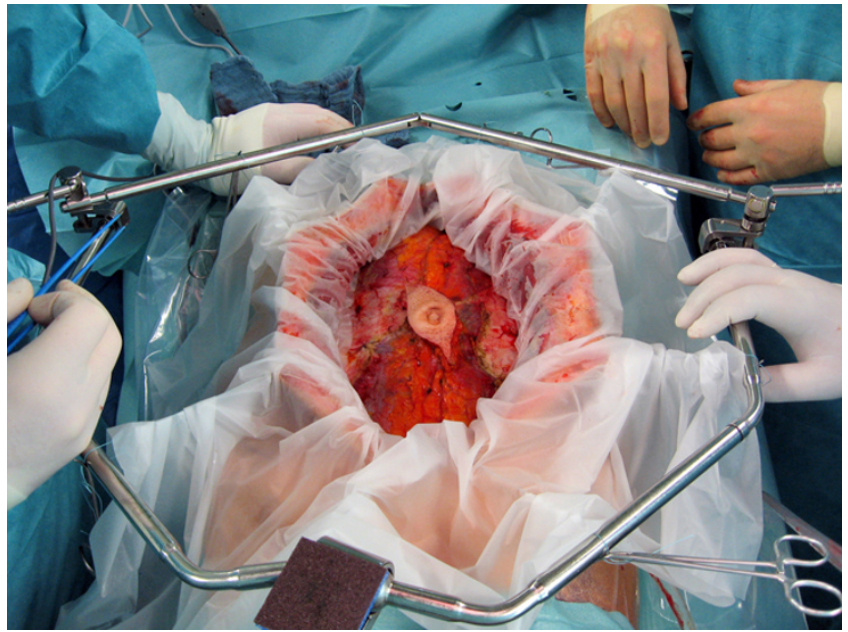

Figure 2

Omphalectomy in a patient with umbilical tumor infiltration.

obtain complete macroscopic cytoreduction (CCR-0/1) as a precondition for the application of HIPEC. The residual disease is classified intraoperatively using the completeness of cytoreduction (CCR) score. CCR-0 indicates no visible residual tumor and CCR-1 residual tumor nodules $\leq 2.5 \mathrm{~mm}$. CCR-2 and CCR-3 indicate residual tumor nodules between $2.5 \mathrm{~mm}$ and $2.5 \mathrm{~cm}$ and $>2.5 \mathrm{~cm}$, respectively [14].

\section{Hyperthermic intraperitoneal chemotherapy}

In case of complete macroscopic cytoreduction (CCR-0/1) CRS is followed by hyperthermic intraperitoneal chemotherapy (HIPEC). The theoretical advantage of the intraperitoneal distribution of cytostatics is a high local concentration of the used agents and reduced systemic toxicity. In vitro studies could show that hyperthermia may potentiate the cytostatic effects. For example an improved tissue penetration could be shown for cisplatin. Moreover, hyperthermia leads to direct cytotoxic effects such as protein denaturation, induction of apoptosis and inhibition of angiogenesis [15].

For the performance of HIPEC one inflow and three outflow drainages are placed subphrenically and in the small pelvis. The cytostatic agent is applied via the inflow drainage using a roller pump and heat exchanger in a closed system that allows perfusate circulation (Fig. 3). The intraperitoneal temperature is monitored by two sensors placed in the inflow catheter and in the Douglas pouch. The intraperitoneal temperature should reach $41-42^{\circ} \mathrm{C}$ leading to an inflow temperature of about $43^{\circ} \mathrm{C}$.

Until today the cytostatic agents, combinations and concentrations used for HIPEC are not standardized for all 


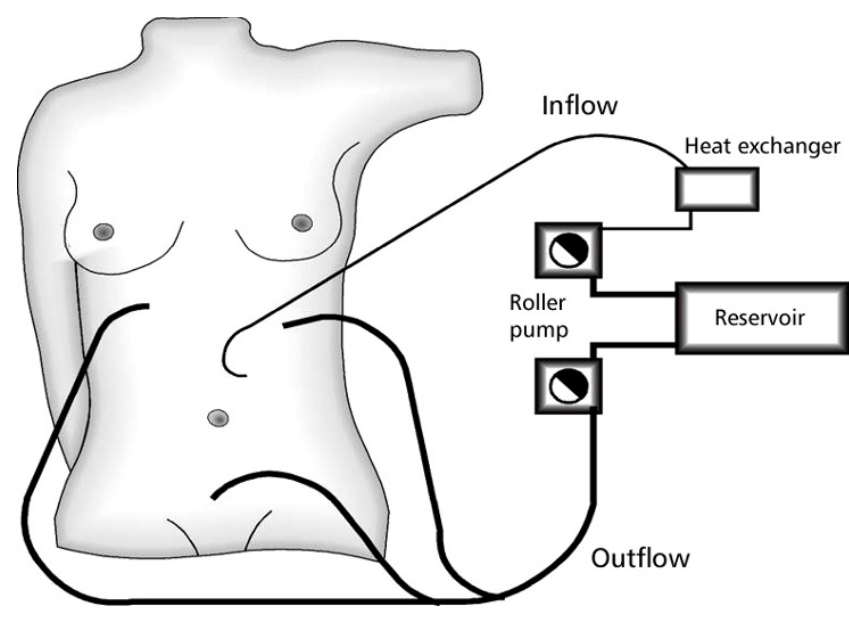

Figure 3

Schematic diagram of HIPEC procedure. peritoneal carcinomatosis centers worldwide. Thus, numerous different protocols are used for the different tumor entities. The perfusion times ranges from 30 to 120 minutes depending on the protocol and the drug used. Moreover, numerous different drugs and drug combinations are used (Table 1). HIPEC can be performed in open or closed abdomen technique. One of the leading advantages of the open technique is a better control of the intraperitoneal circulation and uniform distribution of the cytostatic agents. An important disadvantage is the increased risk of contamination compared to the closed abdomen technique. Although a comparism of the existing studies is difficult there seem to be no significant differences between the two techniques regarding morbidity and mortality rates as well as patient survival [16].

\section{Preoperative diagnostics and patient selection}

Preoperative patient selection plays a pivotal role for the success of CRS and HIPEC regarding clinical as well as oncological patient outcome. Thus, preoperative diagnostics including physical examination, laboratory parame-

Table I: Selected studies with CRS and HIPEC in patients with peritoneal carcinomatosis of different origin.

\begin{tabular}{|c|c|c|c|c|c|c|c|c|}
\hline \multirow[t]{2}{*}{ Author, year } & \multirow[t]{2}{*}{$\mathbf{n}$} & \multirow[t]{2}{*}{ Tumor entity } & \multirow[t]{2}{*}{$\begin{array}{c}\text { Cytostatic } \\
\text { agent(s) }\end{array}$} & \multirow{2}{*}{$\begin{array}{c}\text { Morbidity } \\
{[\%]}\end{array}$} & \multirow{2}{*}{$\begin{array}{c}\text { Mortality } \\
{[\%]}\end{array}$} & \multirow{2}{*}{$\begin{array}{c}\text { Median survival } \\
\text { [months] }\end{array}$} & \multirow{2}{*}{$\begin{array}{c}\text { Overall survival } \\
{[\%]}\end{array}$} & \multirow{2}{*}{$\begin{array}{c}\begin{array}{c}\text { Survival } \\
\text { CCR-0/I }\end{array} \\
{[\%]}\end{array}$} \\
\hline & & & & & & & & \\
\hline $\begin{array}{l}\text { Verwaal, } \\
2003[25,4 I]\end{array}$ & 105 & CRC & $M M C$ & 35 & 8 & 22 & $28(3-y)$ & 45 (5-y) \\
\hline Glehen, 2004[33] & 506 & CRC & MMC/LOHP & 23 & 4 & 19 & $39(3-y)$ & 47 (3-y) \\
\hline Shen, 2004[34] & 77 & CRC & $M M C$ & 30 & 12 & 16 & $25(3-y)$ & $44(3-y)$ \\
\hline Glehen, 2004[29] & 49 & GC & MMC & 27 & 4 & 10 & $8(5-y)$ & $29(5-y)$ \\
\hline Hall, 2004[45] & 34 & GC & MMC & 35 & 0 & 11 & - & $21(5-y)$ \\
\hline $\begin{array}{l}\text { Yonemura, } \\
2005[30]\end{array}$ & 105 & GC & MMC/DDP & 22 & 3 & 19 & $7(5-y)$ & $27(5-y)$ \\
\hline Feldmann, 2003[35] & 49 & DMPM & DDP & 25 & 0 & 92 & $59(5-y)$ & - \\
\hline Deraco, 2006[36] & 49 & DMPM & $\begin{array}{l}\text { DDP/DXR } \\
\text { DDP/MMC }\end{array}$ & 27 & 0 & - & $57(5-y)$ & - \\
\hline Yan, 2007[27] & 70 & DMPM & $\mathrm{DDP} / \mathrm{DXR}$ & 36 & 3 & 59 & $49(5-y)$ & - \\
\hline Piso, 2004[37] & 19 & OC & DDP; MITO & 28 & 5 & 33 & $15(5-y)$ & $44(5-y)$ \\
\hline Cotte, $2007[38]$ & 81 & OC & DDP & 14 & 3 & 28 & - & - \\
\hline $\begin{array}{l}\text { Di Giorgio, } \\
2008[26]\end{array}$ & 47 & OC & DDP & 21 & 4 & 30 & $17(5-y)$ & $26(5-y)$ \\
\hline
\end{tabular}

CRC: colorectal cancer, GC: gastric cancer, PMP: pseudomyxoma peritonei, OC: ovarian cancer, DMPM: diffuse malignant peritoneal mesothelioma, MMC: mitomycin C, DDP: cisplatin, LOHP: oxaliplatin, DXR: doxorubicin, MITO: mitoxantrone 
ters, tumor markers (CA19-9, CEA, CA125, CA72-4), computed tomography of the chest, abdomen and pelvis with intravenous and oral/rectal contrast and endoscopy with or without endoluminal ultrasonography (colorectal and gastric cancer) are indispensable (Table 2). In some cases additional ultrasound, abdominal magnetic resonance imaging (MRI) and/or PET-CT may be helpful depending on the primary tumor and tumor dissemination [17]. However, Esquivel et al. have shown that preoperative CT-PCI does not correlate with the intraoperative PCI. In 52 patients with peritoneal carcinomatosis of colonic origin from 19 international centers the mean CTPCI was 8.6 vs. 13.2 (Esquivel, SSO 2008). In our experience a leading reason for incomplete macroscopic cytoreduction is the intraoperative finding of disseminated tumor spots in the small bowel region. Thus, staging laparoscopy should be performed if necessary to determine tumor dissemination especially in patients with peritoneal carcinomatosis from gastric cancer but not in patients with DMPM because of the high risk of port side metastasis $[18,19]$. Anyway, the tumor entity should be taken into account. Whereas for example patients with peritoneal carcinomatosis of colonic origin with a PCI $\leq$ 20 qualify for CRS and HIPEC, the PCI in patients with gastric cancer should be $<10$ or $\leq 15[20,21]$. In patients with pseudomyxoma peritonei arising from mucinous neoplasms PCI $>20$ is no absolute exclusion criteria. In these patients tumor grading, extent of mesenteric invasion, liver metastasis and age play an important role in conjunction with PCI [22]. The Peritoneal Surface Malignancy Group defined eight clinical and radiological variables that increase the probability of complete macroscopic cytoreduction in patients with peritoneal carcinomatosis of colonic origin: (1) ECOG performance status $\leq 2$, (2) no evidence of extra-abdominal disease, (3) up to three small, resectable parenchymal hepatic metastases, (4) no evidence of bilary obstruction, (5) no evidence of ureteral obstruction, (6) no evidence of intestinal obstruction at more than one site, (7) small bowel involvement: no evidence of gross disease in the mesentery with several segmental sites of partial obstruction and (8) small volume disease in gastro-hepatic ligament $[20,23]$. In patients with DMPM extra-abdominal and hepatic metastasis, histology, nuclear grade and mitotic count are crucial prognostic factors for preoperative patient selection and oncological outcome [18]. Most experts exclude patients with distant metastasis from primary and recurrent gastric cancer [21]. The ovary consensus panel (OCP) found no absolute contraindications for CRS and HIPEC in patients with ovarian cancer regarding tumor dissemination or metastasis. The access should be individually evaluated. Nevertheless, heart failure and pulmonary compromise preclude the combined treatment concept [24].

\section{Morbidity and mortality}

In the literature morbidity and mortality rates after CRS and HIPEC range from $25 \%$ to $41 \%$ and from $0 \%$ to $8 \%$, respectively (Table 1) [25-38]. Morbidity can be divided in surgery-related and chemotherapy-related complications. Common surgery-related complications are for example postoperative ileus, anastomotic leakage, wound infection, bleeding, thrombosis and lung embolism. The different cytostatic agents used for HIPEC can lead to leucopenia, anemia, thrombopenia, heart, liver or renal toxicity and other side effects.

In a prospective study of 70 patients with DMPM Yan et al. found primary colonic anastomosis, more than four peritonectomy procedures (total anterior parietal peritonectomy, greater omentectomy/splenectomy, subphrenic peritonectomy, pelvic peritonectomy, lesser omentectomy/cholecystectomy) and operating time

Table 2: Preoperative diagnostic workup.

Essential preoperative diagnostics

Clinical investigation

Laboratory testing incl. tumor markers

Computed tomography (CT) of the chest, abdomen and pelvis with oral, rectal and intravenous contrast

Tumor-specific essential diagnostics

CRC: complete colonoscopy

GC: gastroscopy

Useful additional diagnostics (case-dependent)

Ultrasonography

Magnetic resonance imaging (MRI)

Positron emission tomography (PET)/PET-CT

Diagnostic laparoscopy

CRC: colorectal cancer, GC: gastric cancer 
greater than 7 hours to be associated with grade IV morbidity [27]. The grade III and IV morbidity rate were $27 \%$ and $14 \%$, respectively. The perioperative mortality rate was 3\%. Hansson et al. analyzed 123 patients treated with CRS and HIPEC for peritoneal carcinomatosis [39]. The grade III/IV morbidity rate and the treatment-related mortality rate were $41 \%$ and $4 \%$, respectively. Bowel morbidity was associated with electroevaporation or excision of tumor nodes on the small bowel surface. In conclusion, morbitity rates after CRS and HIPEC are relatively high but comparable to other major gastrointestinal surgery. However, in the existing studies the assessment of morbidity is not standardized and therefore often not comparable. Thus, following the consensus statement from Milan in further studies the classification system CTCAE version 3.0 should be used. Morbidity is classified in minor complications (grade 0 to 2) and major complications (grade 3 to 5). Moreover, the classification system includes 28 categories leading to an efficient assessment of morbidity [40].

\section{Survival rates}

Several studies have shown that CRS and HIPEC as an integrative part of an interdisciplinary cancer treatment concept may improve survival of patients with peritoneal dissemination of different tumor entities such as colorectal cancer (CRC), gastric cancer (GC), ovarian cancer (OC) and diffuse malignant peritoneal mesothelioma (DMPM) (Table 1).

There are two prospective randomized controlled trials (RCT), one non-randomized comparative study and numerous observational studies regarding clinical and oncologiocal outcome of patients with peritoneal carcinomatosis arising from CRC. Verwaal et al. reported a disease-specific survival of 22.2 months after additional CRS and HIPEC vs. 12.6 months after standard systemic treatment with 5-FU and leucovorin [25,41]. In patients with complete macroscopic cytoreduction (CCR-0/1) median survival was 48 months and 5-year survival rate was $45 \%$, respectively. The second RCT was closed after inclusion of only 35 patients during a 4 year accrual period. The 2 -year survival rates were $60 \%$ in both arms [42]. In the comparative study published by Mahteme et al. the median survival in the HIPEC group was 32 months vs. 14 months in the control group. 5-year survival rates were $28 \%$ and 5\% respectively [43]. In the observational studies the overall median survival ranged from 15 to 32 months and from 28 to 60 months after complete macroscopic cytoreduction (CCR0-1), respectively [9].

The prognosis of patients with peritoneal tumor dissemination from GC is poor but could be significantly improved by CRS and HIPEC in selected patients. Six observational studies including between 17 and 154 patients showed median survival rates ranging from 10 to 19 months [28-31,44,45]. The 5-year survival rates after complete macroscopic cytoreduction (CCR-0/1) were $21 \%, 27 \%, 29 \%, 31 \%$ and 32\%, respectively. Yonemura et al. could show in a multivariate analysis that the completeness of cytoreduction is a highly significant factor for the prediction of patient survival. Moreover, low PCI as well as P1/P2 using the Japanese classification or stage I/ II using the Lyon classification indicating limited extent of peritoneal tumor dissemination were associated with better prognosis [46].

Cytoreductive surgery has already been shown to improve survival of patients with stage III and IV ovarian cancer previous to introduction of the combined treatment concept with CRS and HIPEC [10]. Nevertheless, further improvement of long-term survival is reported for CRS and HIPEC in selected patients. In several studies the median survival rates range from 28 to 46 months and 5year survival rates from 15 to $50 \%$ [26].

DMPM is a rare disease with relatively low incidence. Thus, in the systemic review published by Yan et al. survival data of only seven studies including 12 to 100 patients are reported [47]. In these studies median survival ranges between 34 and 92 months and the 5-year survival rates between $33 \%$ and 59\%, respectively. All studies showed a significant improvement of survival compared to historical controls. Nevertheless, a prospective randomized controlled trial comparing the best available therapy - especially after introduction of permetrexed for the systemic treatment of DMPM - with or without CRS and HIPEC is still not available.

\section{Quality of life after CRS and HIPEC}

Despite relatively high morbidity rates and consecutive initial impairment of quality of life (QoL) several studies could show an improvement of QoL after CRS and HIPEC in long-term survivors [48-52]. McQuellon et al. reported an initial decrease of physical, functional and well-being scores with an increase relative to baseline levels during follow-up at 3, 6 and 12 months. One year after surgery $74 \%$ of the patients resumed $>50 \%$ of their normal activities [49]. In another publication McQuellon et al. concluded that acceptable QoL, return of functional status and reduced pain can be attained 3 to 6 months after CRS and HIPEC. However, a significant number of patients show depressive symptoms at the time of surgery $(32 \%)$ as well as one year after surgery (24\%) [52]. Schmidt et al. evaluated QoL after CRS and HIPEC in 67 patients with peritoneal carcinomatosis using the EORTC QLQ-C30 questionnaire. The mean score for global health status of long-term survivors was significantly decreased compared to the control population (62.6 vs. 73.3 ) showing particularly an impairment of role and social functioning [48]. 
Tuttle et al. showed a return of QoL measurements to baseline 4 months after surgery in a prospective analysis of 35 patients. Eight and twelve months after CRS and HIPEC QoL was significantly improved [51]. In conclusion, the existing studies show that CRS and HIPEC can be performed with acceptable postoperative QoL and even may improve QoL in a selected part of long-term survivors.

\section{Conclusion}

Cytoreductive surgery and hyperthermic intraperitoneal chemotherapy provide a promising therapeutic option for highly selected patients with peritoneal carcinomatosis arising from different malignancies such as colorectal cancer, gastric cancer, ovarian cancer or peritoneal mesothelioma. Numerous studies with different levels of evidence have shown that the integration of CRS and HIPEC in an interdisciplinary treatment concept may improve the oncological outcome compared to sole palliative systemic chemotherapy. The completeness of cytoreduction plays a pivotal role for long-term survival. Thus, consequent preoperative diagnostic workup and patient selection is essential. The existing studies also show that the combined treatment concept can be performed with low mortality and acceptable morbidity in specialized centers. The rate of complications is influenced by the extent of surgery and the cytostatic agent used for intraperitoneal application and its concentration. The quality of life is initially impaired by surgery and postoperative complications. Nevertheless, the functional status returns to baseline in most patients during the first 4 moths after surgery. In selected patients QoL may even be improved one year or later after surgery.

However, for most tumor entities prospective randomized controlled trials comparing best available therapy using new therapeutic agents and combined systemic chemotherapy with and without CRS and HIPEC are still not available. Such studies may provide higher levels of evidence in the future and help to determine the significance of CRS and HIPEC as an integrative part of an interdisciplinary cancer treatment strategy in selected patients with peritoneal carcinomatosis.

\section{Competing interests}

The authors declare that they have no competing interests.

\section{Authors' contributions}

GG drafted the manuscript. HJS corrected the manuscript. PP drafted and corrected the manuscript. All authors read and approved the final manuscript.

\section{References}

I. Sadeghi B, Arvieux C, Glehen O, Beaujard AC, Rivoire M, Baulieux I, Fontaumard E, Brachet A, Caillot JL, Faure JL, Porcheron J, Peix JL, François Y, Vignal J, Gilly FN: Peritoneal carcinomatosis from non-gynecologic malignancies: results of the EVOCAPE I multicentric prospective study. Cancer 2000, 88:358-363.

2. Hardy JR, Wiltshaw E, Blake PR, Harper P, Slevin M, Perren TJ, Tan S: Cisplatin and carboplatin in combination for the treatment of stage IV ovarian carcinoma. Ann Oncol I99|, 2:13|-|36.

3. Curtin JP, Malik R, Venkatraman ES, Barakat RR, Hoskins W]: Stage IV ovarian cancer: impact of surgical debulking. Gynecol Oncol 1997, 64:9-12.

4. Akahira Jl, Yoshikawa H, Shimizu Y, Tsunematsu R, Hirakawa T, Kuramoto H, Shiromizu K, Kuzuya K, Kamura T, Kikuchi Y, Kodama S, Yamamoto K, Sato S: Prognostic factors of stage IV epithelial ovarian cancer: a multicenter retrospective study. Gynecol Oncol 200I, 8I:398-403.

5. Yan TD, Brun EA, Cerruto CA, Haveric N, Chang D, Sugarbaker PH: Prognostic indicators for patients undergoing cytoreductive surgery and perioperative intraperitoneal chemotherapy for diffuse malignant peritoneal mesothelioma. Ann Surg Oncol 2007, | 4:4I-49.

6. Eltabbakh GH, Piver MS, Hempling RE, Recio FO, Intengen ME: Clinical picture, response to therapy, and survival of women with diffuse malignant peritoneal mesothelioma. J Surg Oncol 1999, 70:6-12.

7. Neumann V, Muller KM, Fischer M: [Peritoneal mesothelioma incidence and etiology]. Pathologe 1999, 20:169-176.

8. Simon GR, Verschraegen CF, Jänne PA, Langer CJ, Dowlati A, Gadgeel SM, Kelly K, Kalemkerian GP, Traynor AM, Peng G, Gill J, Obasaju CK, Kindler HL: Pemetrexed plus gemcitabine as first-line chemotherapy for patients with peritoneal mesothelioma: final report of a phase II trial. J Clin Oncol 2008, 26:3567-3572.

9. Glockzin G, Ghali N, Lang SA, Agha A, Schlitt H], Piso P: [Peritoneal carcinomatosis. Surgical treatment, including hyperthermic intraperitoneal chemotherapy]. Chirurg 2007, 78: I I02-I 106.

10. Bristow RE, Tomacruz RS, Armstrong DK, Trimble EL, Montz FJ: Survival effect of maximal cytoreductive surgery for advanced ovarian carcinoma during the platinum era: a meta-analysis. J Clin Oncol 2002, 20:1248-1259.

II. Sugarbaker PH, Cunliffe WJ, Belliveau J, de Bruijn EA, Graves T, Mullins RE, Schlag P: Rationale for integrating early postoperative intraperitoneal chemotherapy into the surgical treatment of gastrointestinal cancer. Semin Oncol 1989, I 6:83-97.

12. Sugarbaker PH: New standard of care for appendiceal epithelial neoplasms and pseudomyxoma peritonei syndrome? Lancet Oncol 2006, 7:69-76

13. Jacquet $\mathrm{P}$, Sugarbaker $\mathrm{PH}$ : Clinical research methodologies in diagnosis and staging of patients with peritoneal carcinomatosis. Cancer Treat Res 1996, 82:359-374.

14. Glehen O, Gilly FN: Quantitative prognostic indicators of peritoneal surface malignancy: carcinomatosis, sarcomatosis, and peritoneal mesothelioma. Surg Oncol Clin N Am 2003, | 2:649-67|.

15. Sugarbaker PH: Laboratory and clinical basis for hyperthermia as a component of intracavitary chemotherapy. Int J Hyperthermia 2007, 23:43I-442.

16. Glehen O, Cotte E, Kusamura S, Deraco M, Baratti D, Passot G, Beaujard AC, Noel GF: Hyperthermic intraperitoneal chemotherapy: nomenclature and modalities of perfusion. J Surg Oncol 2008, 98:242-246.

17. Yan TD, Morris DL, Shigeki K, Dario B, Marcello D: Preoperative investigations in the management of peritoneal surface malignancy with cytoreductive surgery and perioperative intraperitoneal chemotherapy: Expert consensus statement. J Surg Oncol 2008, 98:224-227.

18. Deraco M, Bartlett D, Kusamura S, Baratti D: Consensus statement on peritoneal mesothelioma. I Surg Oncol 2008, 98:268-272.

19. Sugarbaker PH, Welch LS, Mohamed F, Glehen O: A review of peritoneal mesothelioma at the Washington Cancer Institute. Surg Oncol Clin N Am 2003, 12:605-62I.

20. Esquivel J, Elias D, Baratti D, Kusamura S, Deraco M: Consensus statement on the loco regional treatment of colorectal cancer with peritoneal dissemination. I Surg Oncol 2008, 98:263-267.

21. Bozzetti F, Yu W, Baratti D, Kusamura S, Deraco M: Locoregional treatment of peritoneal carcinomatosis from gastric cancer. J Surg Oncol 2008, 98:273-276. 
22. Moran B, Baratti D, Yan TD, Kusamura S, Deraco M: Consensus statement on the loco-regional treatment of appendicea mucinous neoplasms with peritoneal dissemination (pseudomyxoma peritonei). J Surg Oncol 2008, 98:277-282.

23. Esquivel J, Sticca R, Sugarbaker $P$, Levine E, Yan TD, Alexander R, Baratti D, Bartlett D, Barone R, Barrios P, Bieligk S, Bretcha-Boix $P$, Chang CK, Chu F, Chu Q, Daniel S, de Bree E, Deraco M, DominguezParra L, Elias D, Flynn R, Foster J, Garofalo A, Gilly FN, Glehen O, Gomez-Portilla A, Gonzalez-Bayon L, Gonzalez-Moreno S, Goodman M, Gushchin V, Hanna N, Hartmann J, Harrison L, Hoefer R, Kane J, Kecmanovic D, Kelley S, Kuhn J, Lamont J, Lange J, Li B, Loggie B, Mahteme H, Mann G, Martin R, Misih RA, Moran B, Morris D, OnateOcana L, Petrelli N, Philippe G, Pingpank J, Pitroff A, Piso P, Quinones M, Riley L, Rutstein L, Saha S, Alrawi S, Sardi A, Schneebaum S, Shen P, Shibata D, Spellman J, Stojadinovic A, Stewart J, Torres-Melero J, Tuttle T, Verwaal V, Villar J, Wilkinson N, Younan R, Zeh H, Zoetmulder F, Sebbag G, Society of Surgical Oncology Annual Meeting: Cytoreductive surgery and hyperthermic intraperitoneal chemotherapy in the management of peritoneal surface malignancies of colonic origin: a consensus statement. Society of Surgical Oncology. Ann Surg Oncol 2007, 14:128-133.

24. Helm CW, Bristow RE, Kusamura S, Baratti D, Deraco M: Hyperthermic intraperitoneal chemotherapy with and without cytoreductive surgery for epithelial ovarian cancer. J Surg Oncol 2008, 98:283-290.

25. Verwaal V], van Ruth S, de Bree E, van Sloothen GW, van Tinteren $H$, Boot $\mathrm{H}$, Zoetmulder FA: Randomized trial of cytoreduction and hyperthermic intraperitoneal chemotherapy versus systemic chemotherapy and palliative surgery in patients with peritoneal carcinomatosis of colorectal cancer. J Clin Oncol 2003, 2 I:3737-3743.

26. Di Giorgio A, Naticchioni E, Biacchi D, Sibio S, Accarpio F, Rocco M, Tarquini S, Di Seri M, Ciardi A, Montruccoli D, Sammartino P: Cytoreductive surgery (peritonectomy procedures) combined with hyperthermic intraperitoneal chemotherapy (HIPEC) in the treatment of diffuse peritoneal carcinomatosis from ovarian cancer. Cancer 2008, I I3:3|5-325.

27. Yan TD, Edwards G, Alderman R, Marquardt CE, Sugarbaker PH: Morbidity and mortality assessment of cytoreductive surgery and perioperative intraperitoneal chemotherapy for diffuse malignant peritoneal mesothelioma - a prospective study of 70 consecutive cases. Ann Surg Oncol 2007, I 4:5 I 5-525.

28. Hirose K, Katayama K, lida A, Yamaguchi A, Nakagawara G, Umeda $S$, Kusaka Y: Efficacy of continuous hyperthermic peritoneal perfusion for the prophylaxis and treatment of peritoneal metastasis of advanced gastric cancer: evaluation by multivariate regression analysis. Oncology 1999, 57:106-II4.

29. Glehen O, Schreiber V, Cotte E, Sayag-Beaujard AC, Osinsky D, Freyer G, Francois Y, Vignal J, Gilly FN: Cytoreductive surgery and intraperitoneal chemohyperthermia for peritoneal carcinomatosis arising from gastric cancer. Arch Surg 2004, 139:20-26.

30. Yonemura $Y$, Kawamura T, Bandou E, Takahashi S, Sawa T, Matsuki $\mathrm{N}$ : Treatment of peritoneal dissemination from gastric cancer by peritonectomy and chemohyperthermic peritoneal perfusion. Br / Surg 2005, 92:370-375.

3I. Cheong JH, Shen JY, Song CS, Hyung WJ, Shen JG, Choi SH, Noh SH: Early postoperative intraperitoneal chemotherapy following cytoreductive surgery in patients with very advanced gastric cancer. Ann Surg Oncol 2007, 1 4:6I-68.

32. Culliford AT 4th, Brooks AD, Sharma S, Saltz LB, Schwartz GK O'Reilly EM, Ilson DH, Kemeny NE, Kelsen DP, Guillem JG, Wong WD, Cohen AM, Paty PB: Surgical debulking and intraperitoneal chemotherapy for established peritoneal metastases from colon and appendix cancer. Ann Surg Oncol 200I, 8:787-795.

33. Glehen $O$, Kwiatkowski $F$, Sugarbaker $P H$, Elias D, Levine EA, De Simone M, Barone R, Yonemura Y, Cavaliere F, Quenet F, Gutman M, Tentes AA, Lorimier G, Bernard JL, Bereder JM, Porcheron J, GomezPortilla A, Shen P, Deraco M, Rat P: Cytoreductive surgery combined with perioperative intraperitoneal chemotherapy for the management of peritoneal carcinomatosis from colorectal cancer: a multi-institutional study. I Clin Oncol 2004, 22:3284-3292

34. Shen P, Hawksworth J, Lovato J, Loggie BW, Geisinger KR, Fleming RA, Levine EA: Cytoreductive surgery and intraperitoneal hyperthermic chemotherapy with mitomycin C for peritoneal carcinomatosis from nonappendiceal colorectal carcinoma. Ann Surg Oncol 2004, I I: I78-186.

35. Feldman AL, Libutti SK, Pingpank JF, Bartlett DL, Beresnev TH, Mavroukakis SM, Steinberg SM, Liewehr DJ, Kleiner DE, Alexander HR: Analysis of factors associated with outcome in patients with malignant peritoneal mesothelioma undergoing surgical debulking and intraperitoneal chemotherapy. I Clin Oncol 2003, $21: 4560-4567$

36. Deraco M, Nonaka D, Baratti D, Casali P, Rosai J, Younan R, Salvatore A, Cabras Ad AD, Kusamura S: Prognostic analysis of clinicopathologic factors in 49 patients with diffuse malignant peritoneal mesothelioma treated with cytoreductive surgery and intraperitoneal hyperthermic perfusion. Ann Surg Oncol 2006, 13:229-237.

37. Piso $\mathrm{P}$, Dahlke $\mathrm{MH}$, Loss $\mathrm{M}$, Schlitt $\mathrm{HJ}$ : Cytoreductive surgery and hyperthermic intraperitoneal chemotherapy in peritoneal carcinomatosis from ovarian cancer. World J Surg Oncol 2004, 2:21.

38. Cotte E, Glehen O, Mohamed F, Lamy F, Falandry C, Golfier F, Gilly $\mathrm{FN}$ : Cytoreductive surgery and intraperitoneal chemohyperthermia for chemo-resistant and recurrent advanced epithelial ovarian cancer: prospective study of 81 patients. World J Surg 2007, 31:1813-1820

39. Hansson J, Graf W, Pahlman L, Nygren P, Mahteme H: Postoperative adverse events and long-term survival after cytoreductive surgery and intraperitoneal chemotherapy. Eur J Surg Oncol 2008.

40. Younan R, Kusamura S, Baratti D, Cloutier AS, Deraco M: Morbidity, toxicity, and mortality classification systems in the local regional treatment of peritoneal surface malignancy. J Surg Oncol 2008, 98:253-257.

4I. Verwaal VJ, Bruin S, Boot H, van Slooten G, van Tinteren H: 8-year follow-up of randomized trial: cytoreduction and hyperthermic intraperitoneal chemotherapy versus systemic chemotherapy in patients with peritoneal carcinomatosis of colorectal cancer. Ann Surg Oncol 2008, 15:2426-2432.

42. Elias D, Delperro JR, Sideris L, Benhamou E, Pocard M, Baton O, Giovannini M, Lasser P: Treatment of peritoneal carcinomatosis from colorectal cancer: impact of complete cytoreductive surgery and difficulties in conducting randomized trials. Ann Surg Oncol 2004, I I:5 I8-521.

43. Mahteme H, Hansson J, Berglund A, Pahlman L, Glimelius B, Nygren $P$, Graf $W$ : Improved survival in patients with peritoneal metastases from colorectal cancer: a preliminary study. $\mathrm{Br}\rfloor$ Cancer 2004, 90:403-407.

44. Fujimoto S, Takahashi M, Mutou T, Kobayashi K, Toyosawa T, Isawa $\mathrm{E}$, Sumida M, Ohkubo H: Improved mortality rate of gastric carcinoma patients with peritoneal carcinomatosis treated with intraperitoneal hyperthermic chemoperfusion combined with surgery. Cancer 1997, 79:884-891.

45. Hall Jj, Loggie BW, Shen P, Beamer S, Douglas Case L, McQuellon R, Geisinger KR, Levine EA: Cytoreductive surgery with intraperitoneal hyperthermic chemotherapy for advanced gastric cancer. J Gastrointest Surg 2004, 8:454-463.

46. Yonemura $Y$, Bandou E, Kawamura T, Endou Y, Sasaki T: Quantitative prognostic indicators of peritoneal dissemination of gastric cancer. Eur J Surg Oncol 2006, 32:602-606.

47. Yan TD, Welch L, Black D, Sugarbaker PH: A systematic review on the efficacy of cytoreductive surgery combined with perioperative intraperitoneal chemotherapy for diffuse malignancy peritoneal mesothelioma. Ann Oncol 2007, 18:827-834.

48. Schmidt U, Dahlke MH, Klempnauer J, Schlitt HJ, Piso P: Perioperative morbidity and quality of life in long-term survivors following cytoreductive surgery and hyperthermic intraperitoneal chemotherapy. Eur J Surg Oncol 2005, 31:53-58.

49. McQuellon RP, Loggie BW, Fleming RA, Russell GB, Lehman AB, Rambo TD: Quality of life after intraperitoneal hyperthermic chemotherapy (IPHC) for peritoneal carcinomatosis. Eur ] Surg Oncol 200I, 27:65-73.

50. McQuellon RP, Loggie BW, Lehman AB, Russell GB, Fleming RA, Shen $P$, Levine EA: Long-term survivorship and quality of life after cytoreductive surgery plus intraperitoneal hyperthermic chemotherapy for peritoneal carcinomatosis. Ann Surg Oncol $2003,10: 155-162$ 
51. Tuttle TM, Zhang Y, Greeno E, Knutsen A: Toxicity and quality of life after cytoreductive surgery plus hyperthermic intraperitoneal chemotherapy. Ann Surg Oncol 2006, 13:1627-1632.

52. McQuellon RP, Danhauer SC, Russell GB, Shen P, Fenstermaker J, Stewart $\mathrm{JH}$, Levine EA: Monitoring health outcomes following cytoreductive surgery plus intraperitoneal hyperthermic chemotherapy for peritoneal carcinomatosis. Ann Surg Oncol 2007, 14:1105-1 II3.

Publish with Bio Med Central and every scientist can read your work free of charge

"BioMed Central will be the most significant development for disseminating the results of biomedical research in our lifetime. " Sir Paul Nurse, Cancer Research UK

Your research papers will be:

- available free of charge to the entire biomedical community

- peer reviewed and published immediately upon acceptance

- cited in PubMed and archived on PubMed Central

- yours - you keep the copyright

Submit your manuscript here:

http://www.biomedcentral.com/info/publishing_adv.asp 